\title{
1. O PROgRAMA de INTERIORIzAÇÃo DAS AÇöES de SAÚde E SANEAMENTO (PIASS) E A SAÚdE DO NORDESTE
}

O Presidente da República, pelo Decreto n. 78.307, de 24 de agosto de 1976, aprovou a aplicação, de agora até 1979, de 40 bilhões de cruzeiras para a saúde e saneamento do NORDESTE. E uma integração de recursas das áreas dos Ministérios da Saúde e do Interior, principalmente, junto com os recursos remanejados do I.N.P.S. e FUNRURAL.

O Grupo Executivo Interministerial é composto de representantes da Secretaria de Planejamento da Presidência da República com as dos órgãos acima citados; a Secretaria Geral do Ministério da Saúde e a SUDENE darão apoio técnico ao novo Programa, quo terá um órgão em cada Estado do Nordeste.

E para a Associação Brasileira de Enfermagem e para os Conselhos RoBionais de Enfermagem de Brande interesse esse programa; a velha aspiração do pessoal de enfermagem de fazer chegar às populações, onde estão, pro bramas de saúde tem afora a oportunidade de poder ter um bom inicio.

Quais serão as diretrizes básicas do PIASS. O Programa de Interiorização das Açōos de Saúde e Saneamento tem sete diretrizes. Citaremos uma e resumiremos quatro outras.

\section{"Art. 2 Constituem diretrizes básicas do Programa:}

"I - ampla utilização de pessoal de nivel auxiliar, recrutado nas próprias comunidades a serem beneficiadas.'

NOTA: Para este ponto é importante o planejamento, uma vez que verbas do próprio programa talvez paseam ser utilizadas para a formação, na Capital de cada Estado do $N E$, de auxiliares de enfermagem e técnicos de enfermagem, inclusive com preparo para assistência ao parto normal e à saúdo da crianga. O Programa deverá ser instalado cam o pessoal que tiver, porém pode evoluir, empregando no futuro pessoal com formação regular. 
Resumo das diretrizes II, III, IV e VI: ênfase no combate às doenças transmissíveis e encaminhamentos de doentes; desenvolvimento de ações de saúde de baixo custo, e disseminação de unidades de saúde tipo miniposto; e ampla participação da comunidade.

Há muito o que fazer. As enfermeiras e todo o pessoal de enfermagem que tenham possibilidade deverão por mãos à obra. Quanto mais cedo iniciarem organizanão de bons projetos integrados, mais oportunidades terão de os ver aprovados para execução. Tudo deve ser feito para o bem da saúde das populações carentes desse vasto Nordeste Brasileiro.

( $H$ G D)

\section{Cinqüienta anos de trabalho da Associação}

Teremos de ler a nossa história. O que fêz a $A B E n$ para conseguir lançar os fundamentos da enfermagem moderna no país está retratado em livro recente, da autoria da docente da Escola de Enfermagem de São Paulo, D. Anayde Corrêa de Carvalho.

$O$ registro histórico obedece às regras da exatidão e evidência. Não é livro de opiniōes, mas de fatos.

Se você não o leu, adquira-o na sede da $A B E$ n.

( $H$ G D) 